\title{
The distribution of the surface-active beetles (Coleoptera: Carabidae, Staphylinidae, Elateridae) in the agricultural landscapes of Northwestern Russia
}

\author{
Olga G. Guseva*, and Alexander G. Koval \\ All-Russian Institute of Plant Protection, Podbelskogo 3, St. Petersburg, Pushkin, 196608, Russia
}

\begin{abstract}
This paper demonstrates that the species composition of the surface-active beetles (Coleoptera: Carabidae, Staphylinidae, Elateridae) in the landscape site is determined by its local crop. The hygrophilous species are most common in areas with dense vegetation. Assemblages of the epigeic beetles in fields of different crops and adjacent habitats (field margins overgrown with shrubs and forbs) are separated from each other. Beetles associated with a leaf litter layer dominate on the field margins, while rarely occurring in the fields. The populations of the surface-active beetles in perennial grass fields and field margins have the highest species richness.
\end{abstract}

\section{Introduction}

Although many species of beetles (Coleoptera), both zoophages and phytophages, occur in boreal agricultural landscapes, mainly on the soil surface, the patterns of their distribution remain understudied. It is only known that the vegetation cover affects the distribution of assemblages of the epigeic (soil-surface) beetles [1-5]. This study aims to fill this gap determining the structure, species richness, and abundance of the epigeic beetles in the different fields and adjacent semi-natural habitats of Northwestern Russia.

\section{Materials and methods}

This paper is based on the data collected during the 2004-2016 period. The characteristics of the areas where the research was conducted are described in our earlier papers $[4,6]$.

The sample included the three groups of beetles: ground beetles (Carabidae), rove beetles (Staphylinidae) and click beetles (Elateridae). The abundance of beetles is estimated by using the wet pitfall traps. Those are made out of 0.5-liter capacity glass jars which have a top diameter of $72 \mathrm{~mm}$. These jars are filled with $150-250 \mathrm{ml}$ of $4 \%$ formalin solution. The traps

\footnotetext{
* Corresponding author: olgaguseva-2011@yandex.ru
} 
were installed each year in May, and trapping continued until August, with collection carried out at weekly intervals.

The data is analyzed using the vegan and pvclust packages in the $\mathrm{R}$ software (https://www.r-project.org/). The rarecurve function helps to analyze the species diversity of beetles in different parts of the agricultural landscape and to build rarefaction curves in order to describe the dependence of the number of species recorded on the sample size. Samples from different biotopes were compared by calculating distance matrices and clustering the species assemblages by different methods: single and complete. The analysis is carried out using the capture data expressed as the number of individuals per 1000 trap-days. These methods were described in detail earlier [6].

\section{Results and discussion}

A total of 130 species of ground beetles (Carabidae), 190 species of rove beetles (Staphylinidae) [7] and 44 species of click beetles (Elateridae) [8] were recorded in the agricultural landscapes of Northwestern Russia. Of them, 80 Carabidae species, 120 Staphylinidae and 24 Elateridae species were observed in the Menkovo Research Station (MRS) agricultural landscapes in the Leningrad Region between 2004-2016. There are few species common in the field can also occur in the field margins: ground beetles Poecilus cupreus (L.), P. versicolor (Sturm), and Harpalus rufipes (DeGeer), rove beetles Dinaraea angustula (Gyll.), Mocyta fungi (Grav.) and Aloconota gregaria (Er.), click beetles Agriotes obscurus (L.), and A. lineatus (L.). Nonetheless, most of the species are distributed very unevenly across the agricultural landscape.

The assessment of the species diversity of the epigeic beetle complexes using rarefaction curves shows that the assemblages from field boundaries and perennial grass (clover and timothy grass) fields have the greatest species richness while the assemblages from clean fallow have the smallest one (Fig. 1). Staphylinidae, Carabidae, and Elateridae reach their lowest levels of biodiversity in the parts with the most intensive tillage (clean fallow - Fig. 1, curve 1). The origin of this difference lies in the desiccation of soil that creates unfavourable conditions for these mesohydrophilic and hydrophilic beetles.
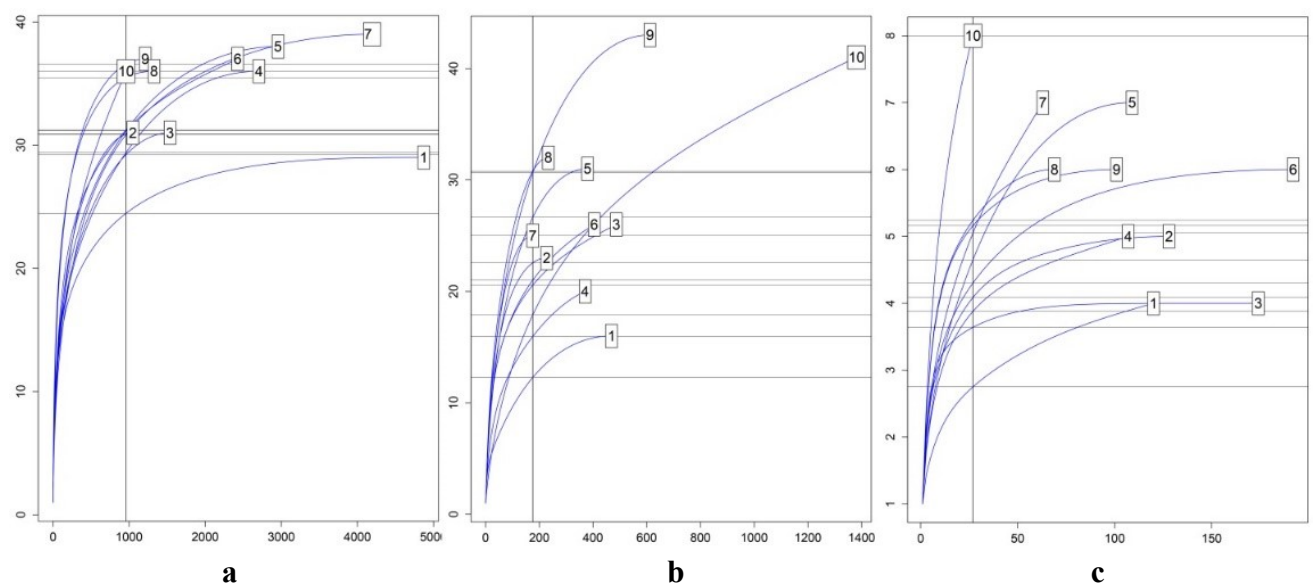

Fig. 1. Rarefaction curves for epigeic beetle complexes inhabiting different fields and field boundaries. Abscissa: sample size, ind.; ordinate: number of species; a - Carabidae; $\mathbf{b}$ - Staphylinidae; $\mathbf{c}-$ Elateridae; 1 - clean fallow; 2, 3- potato fields; 4, 5- spring grain crops; 6 - winter grain crops; 7-9perenual grasses; 10 - field margins and adjacent semi-open habitats. 
The rarefaction curves for ground and rove beetle complexes in clover and timothy grass fields (Fig. 1: 1a, 1b; curves 7-9) show the greatest increase in the number of species with the growing sample size (accumulated number of individuals). This implies that the number of species observed in the clover and timothy grass fields is expected to be higher with the same sample size. The amount of registered species was much smaller in the other fields.

The rarefaction curves for click beetle complexes in field boundaries and adjacent semiopen habitats show the greatest increase in the number of species revealed with the growing sample size (Fig. 1: 1c, curve 10). Within the agricultural landscapes of Northwestern Russia, the highest species richness of Elateridae was recorded in the partly shaded semi-open habitats adjacent to crops [8].

The biodiversity and species composition at the agricultural landscapes site appears to be determined by the local crop. In the MRS landscape, the species needing high humidity are most common in the dense vegetation areas. These species are: ground beetle Loricera pilicornis (F.), rove beetles Stenus spp., click beetles Cidnopus aeruginosus (Ol.), and Ctenicera pectinicornis (L.). This point is also relevant for many other mesohydrophilic species. For instance, ground beetles Pterostichus niger (Schall.), Agonum muelleri Hbst., and Platynus assimilis (Pk.) were recorded only in the plot with a high level of soil improvement, which is responsible both for top phytomass development and higher air humidity in a land-surface air level [4].

This is why perennial grass fields with a heavy vegetation that create favorable conditions for the existence and breeding of hygrophilous species of Staphylinidae, Carabidae and Elateridae families play an important role in agricultural landscapes.

Some of the species of beetles that live in the MRS agricultural landscape were found only in the fields of perennial grasses. Rove beetles Arpedium brachypterum (Grav.), Acidota crenata (F.), Stenus brunipes Steph., S. pusillus Steph., Ontholestes tesselatus (Geoffr.), and click beetle Hemicrepidius hirtus (Hbst.) are the most telling examples of these species. The ground beetle Amara ingenua (Duft.) was also collected only in the perennial grass field [5] in MRS agrolandscape.

In general, the assemblages of the soil-surface beetles in fields are quite different from those in adjacent habitats (namely, field margins overgrown with shrubs and forbs). For instance, beetles that are associated with the leaf litter layer dominate on field margins and forest edges but rarely occur in the fields. They include: ground beetle Trechus secalis Pk., rove beetle Drusilla canaliculata (F.), click beetles Dalopius marginatus (L.), and Athous subfuscus (O.F. Müll.) Moreover, the field margins and adjacent partly shaded semi-open habitats are inhabited with species which have never been registered in the fields of the MRS agricultural landscape throughout the whole period of observations. Those are 8 Carabidae species, 23 Staphylinidae species, and 7 Elateridae species. As the cluster analysis shows, the assemblages of Carabidae, Staphylinidae, and Elateridae in cultivated lands and those in adjacent habitats have the highest distance from each other (Fig. 2). 


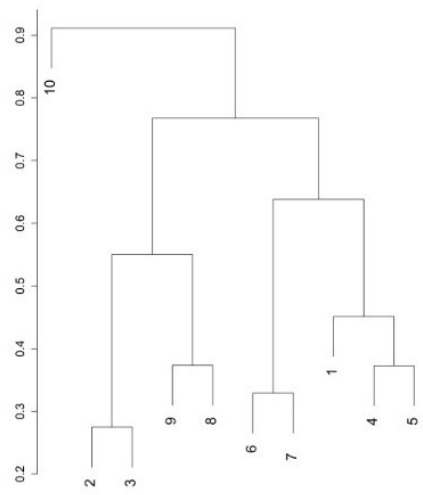

a

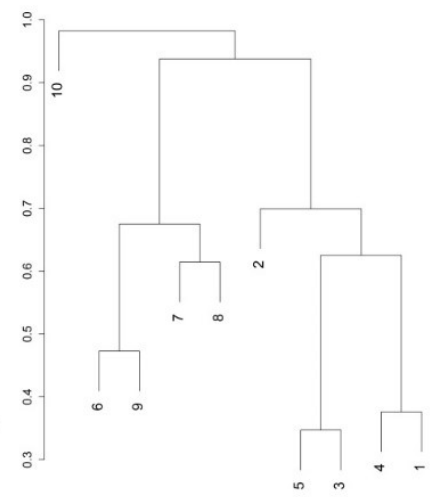

$\mathbf{b}$

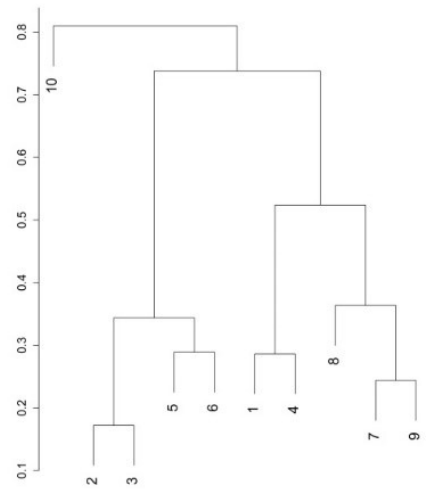

c

Fig. 2. Dendrogram showing the results of grouping by Bray method. Clusterization is performed by the complete method. The distance level is measured along the vertical axis. a - Carabidae; b Staphylinidae; c-Elateridae; 1 - clean fallow; 2, 3 - potato fields; 4, 5-spring grain crops; 6 - winter grain crops; 7-9 - perenual grasses; 10 - field margins and adjacent semi-open habitats.

Thus, the representatives of three completely different families that include both insectivores and herbivores share the similar patterns of distribution among the agricultural landscapes. The biodiversity of beetles fluctuates across the distinct parts of agricultural landscapes. The hygrophilous species are most common in the heavy vegetation areas (field margins and perennial grasses fields). The areas with heavy vegetation have the greatest species richness while the clean fallow fields have the lowest one. The assemblages of the surface-active beetles (Carabidae, Staphylinidae and Elateridae) in fields appear to be separated from those in the adjacent habitats.

\section{References}

1. A. Honěk, Biol. Hortic. \& Agric., 15 (1997)

2. M.D. Eyre, M.L. Luff, J. Coast. Res., 21, 5 (2005)

3. A.G. Koval, Carabid beetles (Coleoptera, Carabidae) of potato crops in European part of Russia and adjacent territories (Rus. Entomol. Soc., St. Petersburg, 2009)

4. O.G. Guseva, A.G. Koval, Entomol. Rev., 95, 8 (2015)

5. O.G. Guseva, A.G. Koval, Acta Biol. Sib., 5, 1 (2019)

6. O.G. Guseva, Acta Biol. Sib., 4, 3 (2018)

7. O.G. Guseva, Abstract diss. ... doct. biol. sc. SPb. (2014)

8. A.G. Koval, O.G. Guseva, Entomol. Rev., 99, 6 (2019) 